\title{
PENGGUNAAN MODEL WATERFALL DALAM PERANCANGAN APLIKASI PENJUALAN KOSMETIK BERBASIS WEB
}

\author{
Frieyadie; Ummi Fatayat \\ ${ }^{1}$ Sistem Informasi \\ Sekolah Tinggi Manajemen Informatika dan Komputer Nusa Mandiri \\ www.nusamandiri.ac.i \\ frieyadie@nusamandiri.ac.id \\ ${ }^{2}$ Sistem Informasi \\ Universitas Bina Sarana Informatika \\ www.bsi.ac.id \\ fatayatummi@gmail.com
}

\begin{abstract}
Abstrak
Perkembangan teknologi ini membawa pengaruh yang cukup besar dalam segala bidang, salah satunya di bidang penjualan barang. Peran perdagangan dalam persaingan bisnis menuntut lebih kreatif dan inovatif agar konsumen tetap tertarik dengan produk yang akan di pasarkan dan beberapa penjualannya masih konvensional sehingga mengalami kesulitan dalam pembuatan laporan penjualan dengan media kertas, yang menyebabkan dokumen sering hilang dan mudah rusak. Proses pemesanan barang kosmetik hanya dilakukan melalui telepon atau datang langsung ke tempat tersebut yang kemudian akan dicatat dalam buku pemesanan, sehingga memungkinkan pada saat proses berlangsung akan terjadi kesalahan dalam pencatatan. Untuk menjawab permasalahan diatas dibutuhkan suatu aplikasi sistem penjualan yang baik, terintegrasi dan dapat dijangkau oleh pengelola sistem, terlebih dijangkau oleh pembeli. Model pengembangan sistem yang digunakan untuk membuat aplikasi sistem penjualan tersebut yaitu Model Waterfall. Tujuan ini untuk menjawab permasalahan-permasalahan yang terjadi saat ini pada took kosmetik.
\end{abstract}

Kata Kunci: Model Waterfall, Aplikasi Penjualan Kosmetik, Perancangan Aplikasi

\section{Abstract}

The development of this technology brings considerable influence in all fields, one of which is in the field of goods sales. The role of trade in business competition demands to be more creative and innovative so that consumers remain interested in the products to be marketed and some of the sales are still conventional so that they have difficulty in making sales reports on paper media, which causes documents to be often lost and easily damaged. The process of ordering cosmetics items is only done by telephone or come directly to the place which will then be recorded in the ordering book, making it possible during the process will occur errors in recording. To answer the above problems, a good, integrated and affordable sales system application is needed by the system manager, especially for buyers. The system development model used to make the sales system application is the Waterfall Model. This purpose is to answer the problems that occur at this time in the cosmetics shop.

Keywords: Waterfall Model, Cosmetic Sales Application, Designing Application

\section{PENDAHULUAN}

Sejalan dengan majunya perkembangan teknologi informasi saat ini membawa pengaruh yang besar dalam kehidupan dan cara pandang manusia terhadap teknologi informasi sekarang maupun masa yang akan datang. Lahirnya media sosial menjadikan pola perilaku masyarakat mengalami pergeseran baik budaya, etika atau norma (Cahyono, 2016).Perkembangan teknologi ini membawa pengaruh yang cukup besar dalam segala bidang, salah satunya di bidang penjualan barang, yaitu kosmetik (Habibah \& miati, 2016). Peran perdagangan dalam persaingan bisnis menuntut lebih kreatif dan inovatif agar konsumen tetap tertarik dengan produk yang akan di pasarkan.

Toko Kosmetik adalah salah satu badan usaha yang bergerak di bidang penjualan, dan beberapa penjualannya masih konvensional(Indah, 
2013), sehingga mengalami kesulitan dalam pembuatan laporan penjualan dengan media kertas, yang menyebabkan dokumen sering hilang dan mudah rusak (Misriati, 2015), serta kurangnya media promosi yang masih mengandalkan media sosial seperti facebook dan instagram saja. Atau bahkan pemesanan barang kosmetik hanya dilakukan melalui telepon atau datang langsung ke tempat tersebut yang kemudian akan dicatat dalam buku pemesanan (Frieyadie, 2014), sehingga memungkinkan pada saat proses berlangsung akan terjadi kesalahan dalam pencatatan (Setiawati, 2015).

Transaksi secara manual juga akan sering terjadi kesulitan dalam mengontrol stok barang (Utami, 2014), dan juga akan membutuhkan waktu yang lama dalam pencarian data sehingga akan kurang efektif (Abdurahman, 2017). Penjual juga harus mengantarkan sendiri barang yang akan dikirim ke jasa pengiriman karena penjual belum menyediakan layanan pengambilan barang (Nugroho \& Sudaryanto, 2013). Sedangkan untuk mendapatkan informasi mengenai keberangkatan barang, konsumen juga masih harus menghubungi pihak penjual melalui telepon (Susafa'ati, 2016)

Agar Toko Kosmetik bisa bersaing dalam menjalankan bisnisnya, sebuah website bisa menjadi solusi yang dapat menyediakan informasi produk yang diinginkan oleh konsumen. Selain itu, konsumen dapat membeli produk tanpa harus datang ke toko dengan harapan dapat mempermudah proses penjualan, pendataan konsumen dan juga pengiriman produk tersebut. Salah satu sarana yang diperlukan untuk mendukung sistem pengolahan informasi yang handal tersebut adalah komputer (Arjaka, 2010). Mempromosikan produk dengan menggunakan website juga akan lebih banyak mengguntungkan dan mempermudah proses pengembangan serta dapat menghemat biaya (Hastanti, Purnama, \& Pacitan, 2015). Model pengembangan sistem yang digunakan dalam penelitian ini yaitu model Waterfall (Aediyansyah, 2018) . Tujuan penelitian ini mempermudah pembuatan laporan penjualan dengan media yang sudah terkomputerisasi. Membuat dokumen penjualan terdata dengan baik, tidak lagi ada pendataan yang ganda. Kontrol stok barang menjadi lebih baik dan pencarian data-data barang ataupun data-data transaksi penjualan.

\section{METODE PENELITIAN}

\section{Jenis Penelitian}

Penelitian ini menggunakan pendekatan kuantitatif dan berupa penelitian terapan.

\section{Target/Subjek Penelitian}

Target/subjek penelitian (untuk penelitian kualitatif) atau populasi-sampel (untuk penelitian kuantitatif) perlu diurai dengan jelas dalam bagian ini. Perlu juga dituliskan teknik memperoleh subjek (penelitian kualitatif) dan atau teknik samplingnya (penelitian kuantitatif).

\section{Model Pengembangan Sistem}

Model yang digunakan pada pengembangan perangkat lunak ini menggunakan model waterfall yang terbagi menjadi lima tahapan, yaitu:

1. Analisa Kebutuhan Perangkat Lunak

Proses pengumpulan kebutuhan dilakukan secara insentif, mulai dari teknik pengumpulan data secara langsung atau observasi yang dilakukan penulis untuk mengamati proses penjualan pada Toko Kosmetik. Dengan analisis kebutuhan sistem, diharapkan sistem yang akan dibangun dapat diuraikan secara detail menjadi komponen dasar dengan tujuan identifikasi, mengevaluasi permasalahan dan kebutuhan yang diharapkan, dan analisis ini juga dilakukan untuk menjamin bahwa sisytem yang digunakan sesuai dengan kebutuhan dari obyek.

2. Perancangan (Design)

Dalam tahap selanjutnya dilakukan perancangan pembuatan model dari sistem dengan cara merancang perangkat lunaknya seperti UML, ERD, merancang input dan outputnya, merancang database dan web design atau interfacenya.

3. Pengkodean (Code Generation)

Pada tahap ini hasil dari fase-fase sebelumnya dituangkan dalam penulisan kode-kode dengan menggunakan bahasa pemrograman yang dapat dimengerti oleh komputer. Hasil dari design atau perancangan mulai diterjemhkan ke dalam bahasa mesin melalui bahasa pemrograman salah satunya yaitu bahasa PHP.

\section{Pengujian (Testing)}

Pengujian merupakan tahap kritis dari jaminan perangkat lunak dalam mempresentasikan apakah sistem sudah benar dan sesuai kebutuhan. Dilakukan setelah kode program selesai dibuat dan program dapat berjalan.

5. Pemeliharaan (Support)

Pada tahap ini, merupakan tahap pemeliharaan atau maintenance terhadap aplikasi yang ada. Pemeliharaan secara rutin meliputi penataan ulang database, melakukan backup dan update data.

\section{Data, Intrumen, dan Teknik Pengumpulan Data}

Untuk menunjang penulisan tugas akhir ini, penulis menggunakan beberapa metode pengumpulan data yaitu:

1. Observasi (Field research) 
Pada tahap ini pengumpulan data dilakukan dengan mengamati proses kegiatan jual beli pada Toko Kosmetik.

2. Wawancara (Conversation research)

Pada tahap ini wawancara dilakukan langsung kepada pemilik Toko Kosmetik untuk mendapatkan data, dimana penulis melakukan pengumpulan data dengan cara bertanya langsung kepada pemilik.

3. Studi Pustaka (Library research)

Untuk melengkapi informasi-informasi yang berkaitan dengan judul tugas akhir ini, penulis mengumpulkan data dari sumber-sumber yang berhubungan dengan penyusunan Tugas Akhir ini. Sumber-sumber bacaan ini dapat berupa skripsi, tugas akhir, artikel, jurnal atau sumber dari situs internet.

\section{HASIL PENELITIAN DAN PEMBAHASAN}

\section{Analisis Kebutuhan Perangkat Lunak}

Langkah pertama yang dilakukan pada rancangan sistem pemesanan kosmetik yang diterapkan, penulis mengidentifikasi kebutuhan yang diperoleh berdasarkan kebutuhan pengguna dan kebutuhan sistem. Halaman ini terbagi menjadi tiga tampilan. Tampilan pertama untuk administrator, yang kedua halaman untuk member, dan yang ketiga halaman untuk pengunjung.

1. Halaman Untuk Bagian Penjualan
a. Dapat mengelola data barang.
b. Mengelola data transaksi penjualan.
c. Pada halaman ini admin dapat melihat pesanan yang masuk.
d. Dapat menginput produk, mengedit dan melihat pesanan yang masuk.
e. Dapat melihat laporan hasil transaksi.

2. Halaman Untuk Pembeli
a. Pada halaman ini pembeli dapat melihat produk-produk yang terdapat pada website ini.
b. Pembeli dapat melakukan login.
c. Pembeli dapat masuk ke keranjang belanja.
d. Dapat melakukan konfirmasi pembayaran pesanan dan melihat status pesanan produk dan nomor resi pesanan.

3. Halaman Untuk Pengunjung

a. Pada halaman ini pengunjung dapat melihat produk-produk yang terdapat pada website ini.

b. Pengunjung dapat melihat tata cara pemesanan atau order kosmetik dan tata cara pembayaran.

c. Pengunjung juga dapat melakukan pendaftaran.

\section{Perancangan Perangkat Lunak}

1. Perancangan Sistem Perangkat Lunak

Perancangan aplikasi sistem penjualan kosmetik ini dengan mengunakan rancangan usecase diagram. Diagram ini untuk menampilkan rancangan sistem dilihat dari fungsional sistem, yang dirancang.

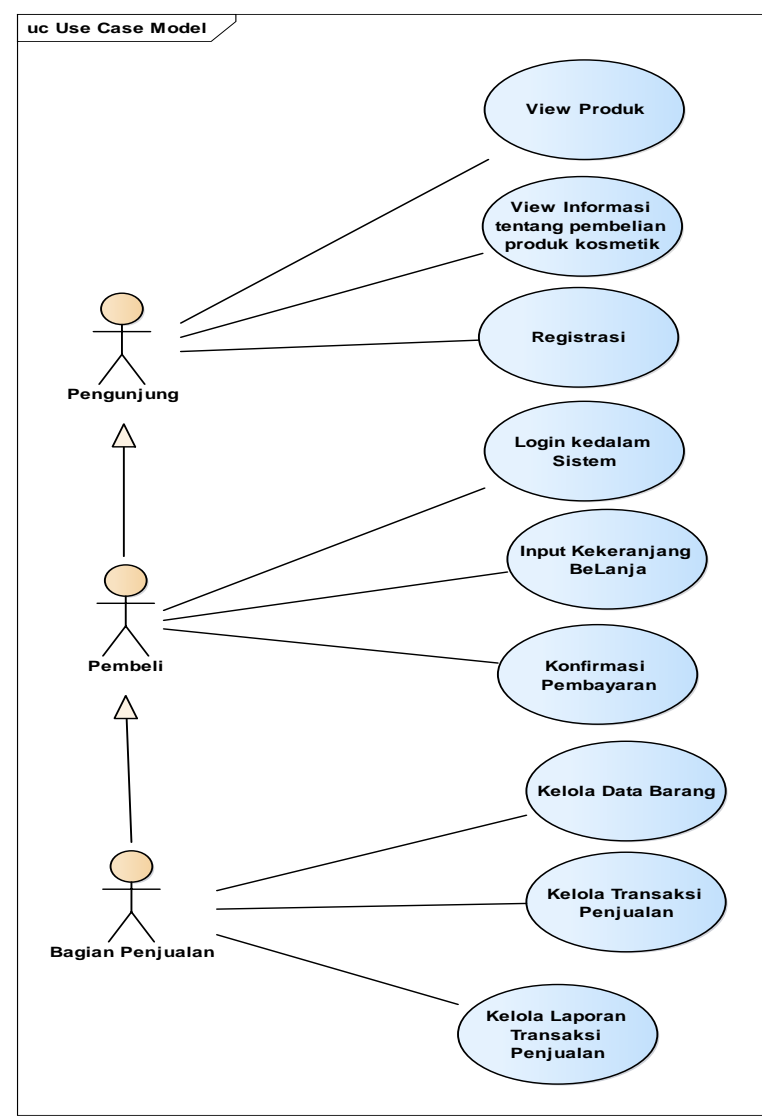

Gambar 1. Usecase Diagram Aplikasi Sistem Penjualan Kosmetik

Di sini saya akan menjelaskan tabel scenario untuk use case "Login kedalam Sistem".

Tabel. 1 Sekenario Use Case Login

\begin{tabular}{lll}
\hline $\begin{array}{l}\text { Use Case } \\
\text { Name }\end{array}$ & $:$ Login Kedalam Sistem \\
\hline $\begin{array}{l}\text { Use case } \\
\text { Description }\end{array}$ & $\begin{array}{l}\text { Pengguna masuk ke Sistem } \\
\text { untuk mengakses } \\
\text { fungsionalitas sistem. }\end{array}$ \\
\hline Actors & $:$ Pembeli, Bagian Penjualan \\
\hline Pre-Condition & $\begin{array}{l}\text { Sistem harus terhubung ke } \\
\text { jaringan internet. }\end{array}$ \\
\hline $\begin{array}{l}\text { Post - } \\
\text { Condition }\end{array}$ & $\begin{array}{l}\text { Setelah login berhasil, pesan } \\
\text { berhasil ditampilkan untuk } \\
\text { dilihat Pengguna }\end{array}$ \\
\hline & \multicolumn{1}{c}{ Step } \\
\hline Main Scenarios & Serial \\
\hline
\end{tabular}




\begin{tabular}{lll}
\hline & No. & \\
\hline Actor & 1 & $\begin{array}{l}\text { Enter Username } \\
\text { Enter Password }\end{array}$ \\
\hline \multirow{2}{*}{3} & $\begin{array}{l}\text { Validate Username, } \\
\text { Password }\end{array}$ \\
\hline & $\begin{array}{l}\text { Mengizikan } \\
\text { Mengakases Sistem } \\
\text { Sesuai dengan hak }\end{array}$ \\
\hline
\end{tabular}

\begin{tabular}{lll}
\hline & & akses \\
\hline Extensions & 2a & $\begin{array}{l}\text { Invalid Username } \\
\text { System menampilkan } \\
\text { pesan error }\end{array}$ \\
\hline & Invalid Password \\
& $\begin{array}{l}\text { System menampilkan } \\
\text { pesan error }\end{array}$ \\
\hline
\end{tabular}

2. Perancangan Database

Perancangan database utama dengan menggunakan Entity Relationship Diagram (ERD), disini menterjemahkan permodelan data secara abstrak. Berikut rancangan ERD.

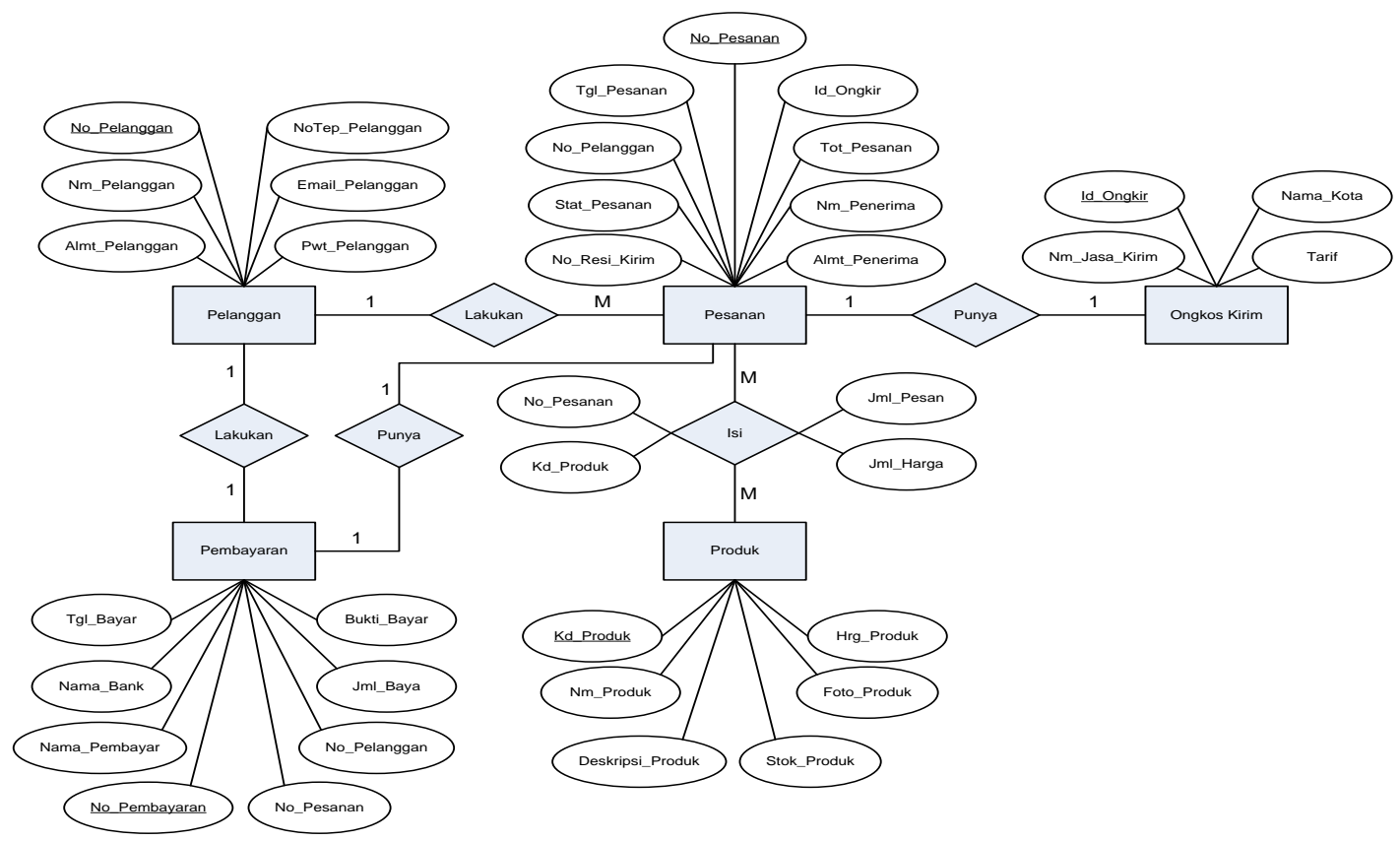

Gambar 2. Entity Relationship Diagram (ERD) Aplikasi Sistem Penjualan Kosmetik

Berikut akan ditampilkan rancangan Logical Record Structure, dimana untuk menunjukan alur logika dari suatu record.

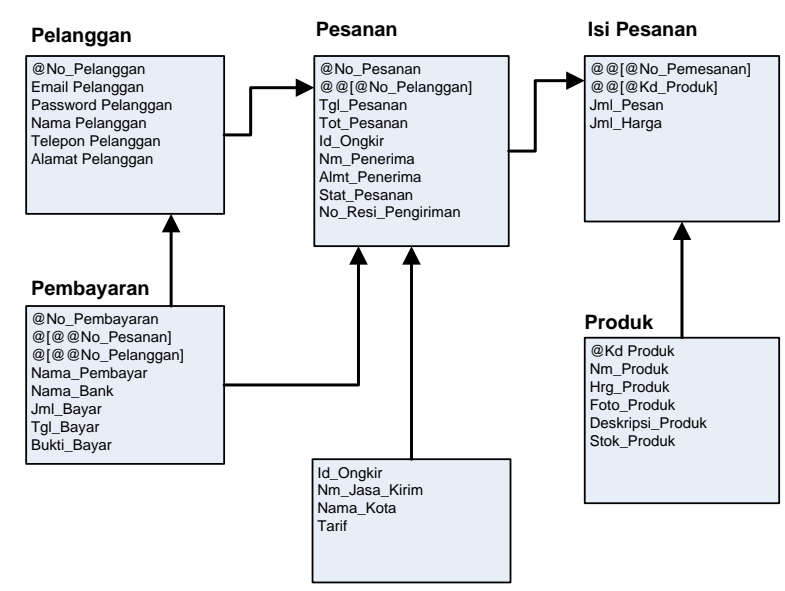

Gambar 3. Logical Record Structure Aplikasi Sistem Penjualan Kosmetik
Implementasi database pada aplikasi sistem penjualan kosmetik dengan menggunakan MySQL.

3. Perancangan Navigasi Aplikasi Sistem Penjualan Kosmetik

a. Navigasi Halaman Pembeli 


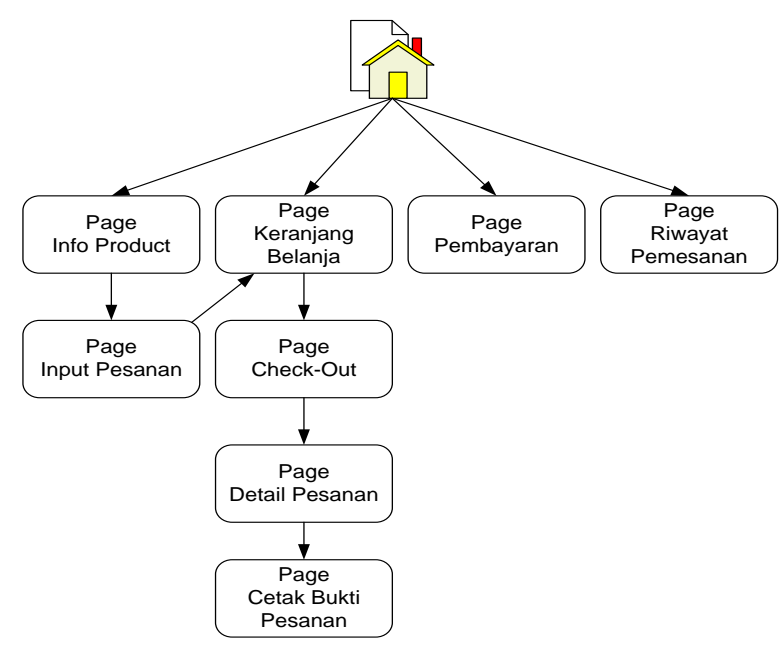

Gambar 4. Navigasi Aplikasi Sistem Penjualan Kosmetik Halaman Pembeli

b. Navigasi Halaman Bagian Penjualan

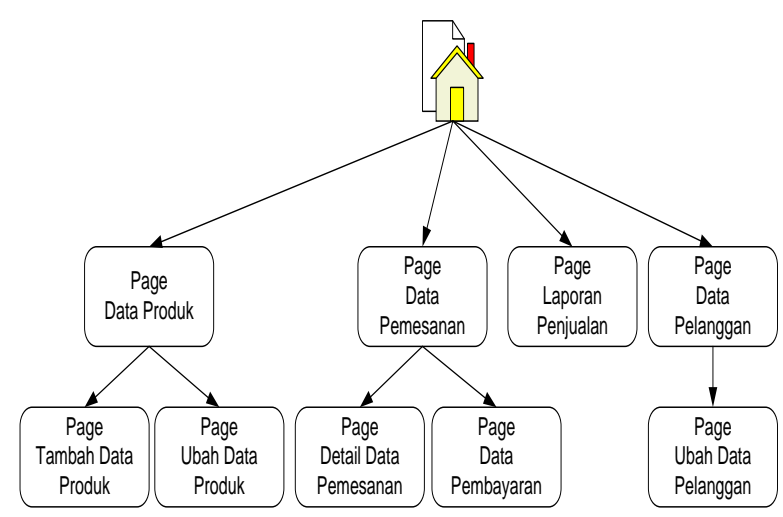

Gambar 5. Navigasi Aplikasi Sistem Penjualan Kosmetik Halaman Bagian Penjualan

4. Rancangan User Inteface

a. Halaman Pelanggan Keranjang

Pada halaman ini pelanggan bisa melihat barang yang sudah di masukan ke kerannjang sebelumnya lalu klik checkout.

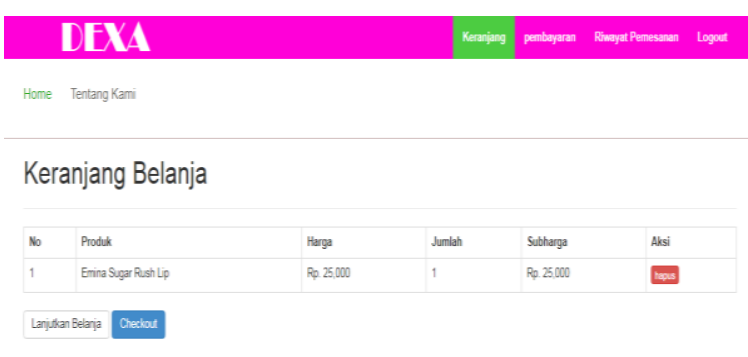

Gambar 6. Pelanggan Keranjang b. Halaman Pelanggan Checkout

Pada halaman ini pelanggan bisa memilih jasa kurir dan mengisi alamat lengkap.

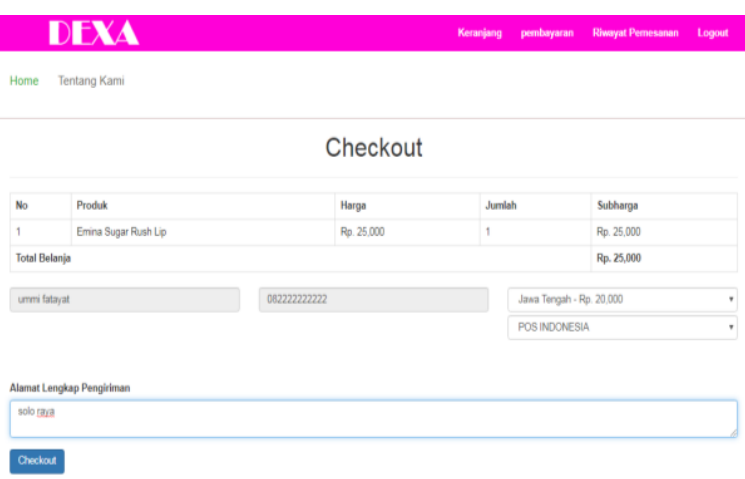

Gambar 7. Pelanggan Checkout

c. Halaman Pelanggan Detail Pesanan

Pada halaman ini pelanggan dapat melihat secara detail pesanan tersebut dan segera konfirmasi pembayaran.

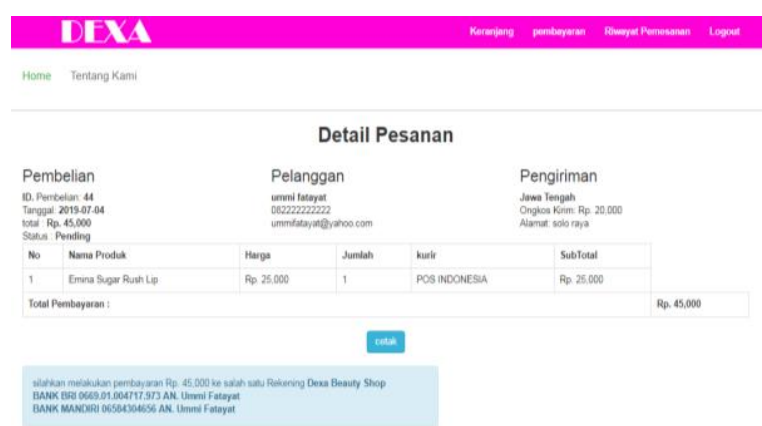

Gambar 8. Pelanggan Detail Pesanan

d. Halaman Pelanggan Konfirmasi Pembayaran Halaman ini berfungsi untuk proses transaksi pembelian dengan cara memasukan identitas orang tersebut.

\section{DEXA}

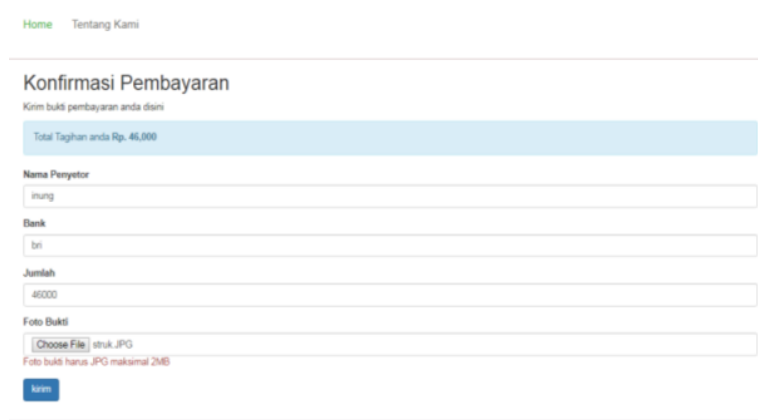

Gambar 9. Pelanggan Konfirmaasi Pembayaran

e. Halaman Pelanggan Riwayat Belanja 
Pada halaman ini pelanggan bisa melihat status pesanan barang tersebut.

\section{DEXA}

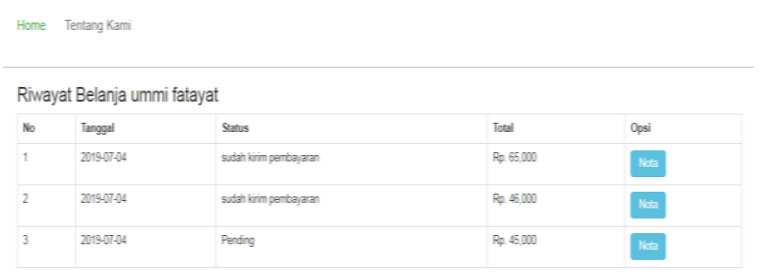

Gambar 10. Pelanggan Riwayat Belanja

Untuk menjawab permasalahan-permasalahan yang ada, maka aplikasi sistem penjualan kosmetik menangkap semua data transaksi yang dilakukan oleh pelanggan.

f. Halaman Bagian Penjualan Data Transaksi Pemesanan

Halaman ini berfungsi untuk melihat detail data pesanan pelanggan.

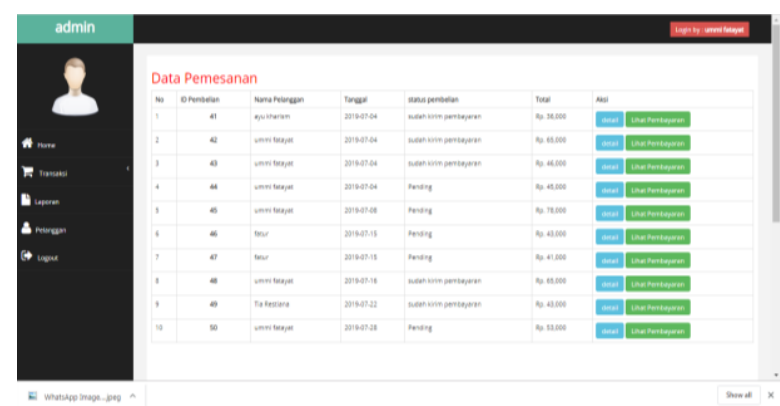

Gambar 11. Data Transaksi Pemesanan

g. Halaman Bagian Penjualan Data Transaksi Detail Pemesanan

Halaman ini berfungsi untuk melihat lebih detail pemesanan pelanggan.

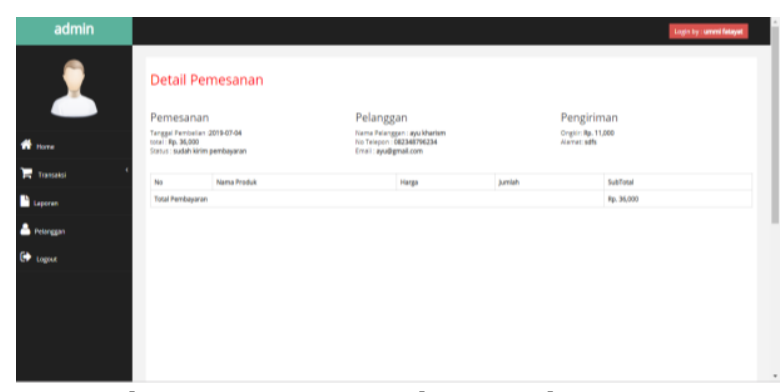

Gambar 12. Data Transaksi Detail Pemesanan

h. Halaman Admin Data Pemesanan Lihat Pembayaran

Halaman ini berfungsi untuk melihat bukti pembayaran dari pesanan pelanggan.

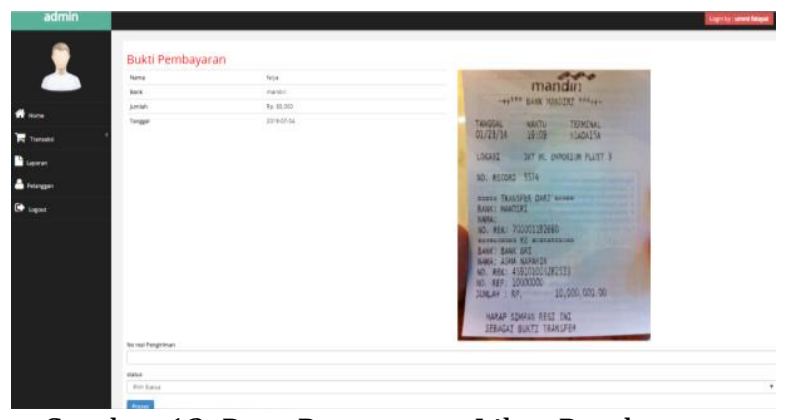

Gambar 13. Data Pemesanan Lihat Pembayaran

\section{Code Perangkat Lunak}

Untuk source code perangkat lunak aplikasi penjualan kosmetik tidak penulis tampilkan, dikarenakan terlalu banyak. Penulis menulis dengan menggunakan bahasa script PHP, dengan dukungan bahasa script lain untuk membangun apliaksi sistem ini.

\section{Pengujian Perangkat Lunak}

Tabel 1. Pengujian Login Pembeli

\begin{tabular}{|c|c|c|c|c|c|}
\hline No & $\begin{array}{l}\text { Skenario } \\
\text { Pengujian }\end{array}$ & Test Case & $\begin{array}{c}\text { Hasil yang } \\
\text { di } \\
\text { Harapkan }\end{array}$ & $\begin{array}{c}\text { Hasil } \\
\text { Penguji } \\
\text { an }\end{array}$ & $\begin{array}{l}\text { Kesimpu } \\
\text { lan }\end{array}$ \\
\hline 1. & $\begin{array}{l}\text { Email dan } \\
\text { Password } \\
\text { tidak diisi } \\
\text { kemudian } \\
\text { klik } \\
\text { tombol } \\
\text { login }\end{array}$ & $\begin{array}{l}\text { Email: (kosong), } \\
\text { Password: (kosong) }\end{array}$ & $\begin{array}{l}\text { Sistem akan } \\
\text { menolak } \\
\text { lalu muncul } \\
\text { peringatan } \\
\text { "Harap } \\
\text { masukan } \\
\text { email/passw } \\
\text { ord }\end{array}$ & $\begin{array}{l}\text { Sesuai } \\
\text { dengan } \\
\text { harapa } \\
\mathrm{n}\end{array}$ & Valid \\
\hline 2 & $\begin{array}{l}\text { Mengetika } \\
\text { n Email } \\
\text { dan } \\
\text { Password } \\
\text { tidak diisi } \\
\text { kemudian } \\
\text { klik } \\
\text { tombol } \\
\text { login }\end{array}$ & $\begin{array}{l}\text { Email : } \\
\text { (ummifatayat@yaho } \\
\text { o.com), Password: } \\
\text { (kosong) }\end{array}$ & $\begin{array}{l}\text { Sistem akan } \\
\text { menolak } \\
\text { lalu akan } \\
\text { muncul } \\
\text { peringatan } \\
\text { "Masukan } \\
\text { email/pass } \\
\text { word } \\
\text { dengan } \\
\text { benar. }\end{array}$ & $\begin{array}{l}\text { Sesuai } \\
\text { dengan } \\
\text { harapa } \\
\mathrm{n}\end{array}$ & Valid \\
\hline 3. & $\begin{array}{l}\text { Mengeti } \\
\text { kan } \\
\text { userna } \\
\text { me } \\
\text { tidak } \\
\text { diisi } \\
\text { dan } \\
\text { passwor } \\
d \text { di isi } \\
\text { kemudi } \\
\text { an klik } \\
\text { tombol } \\
\text { login }\end{array}$ & $\begin{array}{l}\text { Email: (kosong) } \\
\text { Password: (fata) }\end{array}$ & $\begin{array}{l}\text { Sistem akan } \\
\text { menolak } \\
\text { lalu muncul } \\
\text { peringatan } \\
\text { "Masukan } \\
\text { email/pass } \\
\text { word } \\
\text { dengan } \\
\text { benar. }\end{array}$ & $\begin{array}{l}\text { Sesuai } \\
\text { dengan } \\
\text { harapa } \\
\mathrm{n}\end{array}$ & Valid \\
\hline 4. & $\begin{array}{l}\text { Mengeti } \\
\text { kan } \\
\text { userna } \\
\text { me } \\
\text { dengan } \\
\text { benar } \\
\text { dan } \\
\text { mengisi } \\
\text { passwor } \\
d \text { salah } \\
\text { kemudi } \\
\text { an klik } \\
\text { tombol }\end{array}$ & $\begin{array}{l}\text { Email: } \\
\text { (ummifatayat@yaho } \\
\text { o.com) (benar) } \\
\text { Password : (ummi) } \\
\text { (salah) }\end{array}$ & $\begin{array}{l}\text { Sistem akan } \\
\text { menolak } \\
\text { dan } \\
\text { akanmuncul } \\
\text { peringatan } \\
\text { "Masukan } \\
\text { email/pass } \\
\text { word } \\
\text { dengan } \\
\text { benar. }\end{array}$ & $\begin{array}{l}\text { Sesuai } \\
\text { dengan } \\
\text { harapa } \\
\mathrm{n}\end{array}$ & Valid \\
\hline
\end{tabular}




\begin{tabular}{|c|c|c|c|c|c|}
\hline & login & & & & \\
\hline 5. & $\begin{array}{l}\text { Mengeti } \\
\text { kan } \\
\text { userna } \\
\text { me } \\
\text { dengan } \\
\text { salah } \\
\text { dan } \\
\text { mengisi } \\
\text { passwor } \\
d \\
\text { dengan } \\
\text { benar } \\
\text { kemudi } \\
\text { an klik } \\
\text { tombol } \\
\text { login } \\
\end{array}$ & $\begin{array}{l}\text { Email: } \\
\text { (ummifatayat@yaho } \\
\text { o.com) (salah) } \\
\text { Password: (fata) } \\
\text { (benar) }\end{array}$ & $\begin{array}{l}\text { Sistem akan } \\
\text { menolak } \\
\text { dan } \\
\text { akanmuncul } \\
\text { peringatan } \\
\text { "Harap } \\
\text { masukkan } \\
\text { Email/Pass } \\
\text { word } \\
\text { dengan } \\
\text { benar" }\end{array}$ & $\begin{array}{l}\text { Sesuai } \\
\text { dengan } \\
\text { harapa } \\
\mathrm{n}\end{array}$ & Valid \\
\hline 6. & $\begin{array}{l}\text { Mengeti } \\
\text { kan } \\
\text { userna } \\
\text { me } \\
\text { dengan } \\
\text { salah } \\
\text { dan } \\
\text { mengisi } \\
\text { passwor } \\
d \\
\text { dengan } \\
\text { salah } \\
\text { kemudi } \\
\text { an klik } \\
\text { tombol } \\
\text { login }\end{array}$ & $\begin{array}{l}\text { Email: } \\
\text { (ummifatayat@yaho } \\
\text { o.com) (salah) } \\
\text { Password: (ummi) } \\
\text { (salah) }\end{array}$ & $\begin{array}{l}\text { Sistem akan } \\
\text { menolak } \\
\text { dan } \\
\text { akanmuncul } \\
\text { peringatan } \\
\text { "Harap } \\
\text { masukkan } \\
\text { Email/Pass } \\
\text { word } \\
\text { dengan } \\
\text { benar" }\end{array}$ & $\begin{array}{l}\text { Sesuai } \\
\text { dengan } \\
\text { harapa } \\
\mathrm{n}\end{array}$ & Valid \\
\hline $\begin{array}{l}7 \\
\end{array}$ & $\begin{array}{l}\text { Mengetika } \\
\mathrm{n} \text { Email } \\
\text { dan } \\
\text { Password } \\
\text { dengan } \\
\text { lengkap } \\
\text { kemudian } \\
\text { klik } \\
\text { tombol } \\
\text { Login }\end{array}$ & $\begin{array}{l}\text { Email: } \\
\text { (ummifatayat@yaho } \\
\text { o.com), password: } \\
\text { (fata) }\end{array}$ & $\begin{array}{l}\text { Sistem } \\
\text { menerima } \\
\text { akses. Dan } \\
\text { dapat } \\
\text { masuk login. } \\
\text { "Anda } \\
\text { Sukses } \\
\text { Login" }\end{array}$ & $\begin{array}{l}\text { Sesuai } \\
\text { dengan } \\
\text { harapa } \\
\mathrm{n}\end{array}$ & Valid \\
\hline
\end{tabular}

SIMPULAN DAN SARAN

\section{Simpulan}

Berdasarkan pembahasan mengenai pembuatan toko kosmetik berbasis web yang telah dibahas pada bab sebelumnya, penulis dapat memberikan simpulan diantaranya pelanggan bisa menerima informasi secara detail dalam hitungan detik, bukan lagi hari bahkan minggu. Adanya website sistem informasi penjualan kosmetik online ini, memberikan kemudahan bagi para pelanggan dalam memesan tanpa harus datang langsung ke toko. Aplikasi penjualan kosmetik online berbasis web lebih mudah dalam pengelolaan data.

\section{Saran}

Berdasarkan kesimpulan dari pembahasan penjelasan di atas, penulis memberikan beberapa saran sebagai alternatif untuk menjadi seorang web Programmer, selain itu juga dapat dijadikan masukan yang sangat berguna, dengan harapan agar dapat meningkatkan kualitas pengguna aplikasi website toko kosmetik online ini. Untuk itu perlu diperhatikan antara lain: maintenance atau perawatan komputer agar tetap terjaga dari kendala apapun; meskipun sudah menggunakan website sebagai media penyampain informasi kepada masyarakat umum, jangan sampai lemah dengan ancaman-ancaman yang terjadi didunia maya seperti hacking, cracking dan sebagainya; penulis menyarankan agar membackup data apabila sewaktu-waktu ada masalah data tetap ada; hindari Human Error karena dapat menimbulkan kesalahan. Administrator yang bertugas mengupdate data diharapkan mendapat pelatihan terlebih dahulu agar mampu beradaptasi dengan Program yang ada di dalam website; dan untuk mendukung kelancaran dan menghindari error Program, diperlukan pemeliharaan dan pengembangan pada aplikasi website penjualan kosmetik secara online yang dilakukan secara berkala.

\section{DAFTAR REFERENSI}

Abdurahman, M. (2017). SISTEM INFORMASI PENGOLAHAN DATA PEMBELIAN DAN PENJUALAN PADA TOKO KOLONCUCU TERNATE. IJIS - Indonesian Journal On Information System, 2(1). Retrieved from http://ijiswiratama.org/index.php/home/art icle/view/22

Aediyansyah, A. (2018). PERANCANGAN SISTEM INFORMASI PENJUALAN DAUR ULANG BOTOL BEKAS (PET) BERBASIS WEB. Jurnal Riset Informatika, 1(1), 11-16. https://doi.org/10.34288/jri.v1i1.5

Arjaka, S. (2010). MEDIA ELEKTRONIK BERBASIS KOMPUTER SEBAGAI MEDIA DALAM PROSES PEMBELAJARAN. jurnal-online.um.ac.id. Malang.

Cahyono, A. S. (2016). PENGARUH MEDIA SOSIAL TERHADAP PERUBAHAN SOSIAL MASYARAKAT DI INDONESIA. PUBLICIANA, 9(1), 140-157.

Frieyadie, F. (2014). WEB SISTEM INFORMASI BERBASIS W2000 UNTUK DUKUNGAN PEMESANAN DAN PENJUALAN PRODUK SAFETY. Jurnal Pilar Nusa Mandiri, 10(1), 111-116.

https://doi.org/10.33480/PILAR.V10I1.468

Habibah, U., \& miati, S. (2016). PENGARUH KUALITAS PRODUK DAN HARGA TERHADAP KEPUTUSAN PEMBELIAN PRODUK KOSMETIK WARDAH DI KOTA BANGKALAN MADURA. JEB17: Jurnal Ekonomi Dan Bisnis, 1(01). Retrieved from http://jurnal.untagsby.ac.id/index.php/JEB17/article/view/635

Hastanti, R. P., Purnama, B. E., \& Pacitan, I. U. W.-S. P. (2015). Sistem Penjualan Berbasis Web (E- 
Commerce) Pada Tata Distro Kabupaten Pacitan. Bianglala Informatika, 3(2). https://doi.org/10.31294/bi.v3i2.581

Indah, I. N. (2013). Pembuatan Sistem Informasi Penjualan Pada Toko Sehat Jaya Elektronik Pacitan. Speed - Sentra Penelitian Engineering Dan Edukasi, 12(1). https://doi.org/10.3112/SPEED.V12I1.1147

Misriati, T. (2015). RANCANG BANGUN SISTEM PELAYANAN JASA PENGECATAN SUKU CADANG KENDARAAN BERMOTOR. Jurnal Teknik Komputer, 1(1), 123-133. https://doi.org/10.31294/jtk.v1i1.243

Nugroho, A. W., \& Sudaryanto, B. (2013). PENGARUH KINERJA LAYANAN, KEPERCAYAAN DAN KEPUASAN TERHADAP LOYALITAS KONSUMEN DALAM MENGGUNAKAN JASA PENGIRIMAN BARANG. Diponegoro Journal of Management,
2(3), 1-9.

Setiawati, W. (2015). PENYUSUNAN STANDARD OPERATING PROCEDURE (SOP) PADA PT. SKETSA CIPTA GRAHA DI SURABAYA. Agora, 3(1), 514-522. Retrieved from http://publication.petra.ac.id/index.php/ma najemen-bisnis/article/view/2906

Susafa'ati, S. (2016). PELAYANAN CARGO UDARA BERBASIS ONLINE PADA JASA PENGIRIMAN BARANG (STUDI KASUS PADA PT. LANCAR SEMESTA DIRGANTARA). Jurnal Techno Nusa Mandiri, 13(2), 121-128. https://doi.org/10.33480/TECHNO.V13I2.20 4

Utami, R. D. (2014). Sistem Informasi Laporan Keuangan Perusahaan Dagang Berbasis Multiuser (Studi Kasus di Toko Lestari). Jurnal Mahasiswa STEKOM Semarang, 1(1), 117. 